relationships, similarity laws, and the various approximate methods for deriving the flow past blunt and slender bodies and blunt-nosed slender bodies. The second part deals with real gas effects, boundary layers and their interaction with the external flow and low density effects. It is difficult in such a small compass to reconcile the need to provide both the basic analysis and a guide to recent developments. The first part of the book is on the whole successful in this; the second part is perhaps less successful and sections of it are little more than lists of references. The book shows signs of inadequate editing and includes an embarrassingly large errata sheet. The reader will have no difficulty in spotting other minor slips and printer's errors. Few are of serious consequence, but a reader might be puzzled to see on page 169 an analysis that leads to the conclusion that zero absolute temperature is attained at the surface of a body.

However, this is a valuable book that meets a major need in a rapidly expanding field. The research engineer will find much that is helpful and illuminating; the lecturer will find in it a useful framework on which to build a postgraduate course.

A. D. Youne

\section{ELECTRON SPIN RESONANCE}

\section{Zahlenwerte und Funktionen aus Naturwissenschaften und Technik}

Von Landolt-Börnstein. Neue Serie. Gesamtherausgabe: K. H. Hellwege. Gruppe II: Atom- und Molekularphysik. Band 1: Magnetische Eigenschaften freier Radikale. Von H. Fischer. Herausgeber: K. H. Hellwege und A. M. Hellwege. Pp. $\mathrm{x}+154$. (Berlin: Springer-Verlag, 1965.) 68 D.M.

$\mathrm{T}$

HE volumes of Landolt-Börnstein are the authorita. tive reference compilations of exact numerical data for the physical sciences; the "New Series" breaks away from the traditional coverage of well-established subjects to deal, in several smaller books, with newer, rapidly advancing topics of specialist interest. In the first volume to appear Dr. H. Fischer, of the Deutches KunststoffInstitut at Darmstadt, has collected data up to March 1964 concerning the electron spin resonance that can be exhibited by free atoms and radicals when placed in a magnetic field. The tables list, for each identified atom or radical, both the spectroscopic slitting $g$ factor for its unpaired electron and the hyperfine splitting constants $a_{\lambda}$ for its interactions with the magnetic moments of vicinal atomic nuclei $\lambda$. They also give the resonance frequency and method of radical production used and its solvent or crystalline environment.

The book has been prepared essentially for organic chemists since only eight of its one hundred and nineteen pages of tables deal with radicals observed on the irradiation of inorganic crystals; again transition elements, their ions and complexes receive no mention. Also, following the thorough literature references to identified radicals, there are nine pages listing references to poorly diagnosed radicals that have been obtained in polymers or irradiated solids and five to radicals noticed in irradiated proteins, in enzymes or other biological materials.

Every pure or applied scientist who has any interest in free radical chemistry will be grateful to Dr. Fischer for this publication of his comprehensive card index. However, his editors should be warned that in the past two years very many more free radicals have been diagnostically characterized by electron spin resonance, since modern experimental techniques can now be used for the measurement of active free radicals of transient existence, and standardized equipment for their detection is now being manufactured in several countries. Thus to keep this topic up to date, a regularly revised edition of this volume is sure to be required at no more than five-year intervals.
To many scientists, observations of electron spin resonance spectra represent the fruition of theories of wave mechanics as applied to 'odd molecules'. Experimental scientists, particularly organic and biological chemists, however, always find that mathematical theories lag behind the realms of immediate and foreseeable laboratory discoveries. In free radical chemistry this time lag is particularly noticeable. In the first place the free radicals of prime chemical interest are three-dimensional particles of transient existence, while, for the theorist, two-dimensional problems concerning stable radicals usually tax his mathematical capabilities to the full. Secondly, organic chemists do not generate their radicals as isolated particles in a vacuum but as 'free' entities moving about within a liquid. One has merely to glance through the pages of this book to see that these 'free' radicals are physically, as well as chemically, influenced by their environment since measurements of the hyperfine splitting parameters $\left(a_{\lambda}\right)$ of the same radical in different solvents vary far beyond the error limits of experimental measurements. Even more questionable is the correlation of data for 'trapped' radicals generated within rigid media and those for the 'free' radicals that alone must be considered in relation to chemical reactions.

However, while the experimentalist should ask the theorist to pay more attention to the environment of the particles which he selects for mathematical consideration, this book shows that the latter may well reply by asking for many more data concerning $g$ factors of complex radicals.

This book, which maintains the typographical excellence of previous volumes of Landolt-Börnstein, is a timely, welcome addition to reference libraries.

W. A. WATERS

\section{ANALYTICAL BIOLOGY}

Theoretical and Mathematical Biology

Edited by Prof. Talbot H. Waterman and Prof. Harold J. Morowitz. Pp. xvii +426. (New York and London : Blaisdell Publishing Company, a Division of Ginn and Company, 1965.) $100 s$.

THEORETICAL and Mathematical Biology is an anthology by seventeen authors, mostly of considerable reputation, concerning applications to biology of mathematics, computers, physics and chemistry. It is clearly directed at the professional biologist, since the technical terms of that subject are used throughout, with little attempt at definition. The purpose of the book is to convince the biologist that quantitative methods are essential for the future health of biology, and that the education of research workers in that subject should now include extensive training in various quantitative disciplines. I think this implies that biology courses should be lengthened by two years.

The chapters do not hang together well, partly because of the nature of the subject and partly because the chapters seem, on the whole, to have been written independently, apart from the first and final chapters by Waterman, in which he tries to pull the threads together. These two chapters, and some others, are partly historical, and in addition Chapter 2, by Morowitz, is deliberately so.

Chapter 3, by N. Rashevsky, is, in a way, a defence of his work, and that of his students, on mathematical biophysics. This work has been attacked by many biologists because it is not in the main stream of presentday biological research, but it should be judged on its own merits, and this chapter will help people to do so.

Chapter 4, by H. Eyring and D. W. Urry, is concerned with the application of thermodynamics and statistical mechanics to the determination of the rates of chemical reactions, with a view to the elucidation of enzyme 